\title{
Geographic variation in secondary fracture prevention after a hip fracture during 1999-2013: a UK study
}

\author{
A. Shah ${ }^{1}$ - D. Prieto-Alhambra ${ }^{1,2}$ - S. Hawley ${ }^{1}$ - A. Delmestri ${ }^{1}$ - J. Lippett $^{3}$. \\ C. Cooper $^{1,2}$ - A. Judge ${ }^{1,2}$ - M. K. Javaid ${ }^{1,2}$. the REFReSH study team ${ }^{1,2,3}$
}

Received: 21 June 2016 / Accepted: 13 October 2016 / Published online: 3 November 2016

(C) International Osteoporosis Foundation and National Osteoporosis Foundation 2016

\begin{abstract}
Summary Fragility fractures of the hip have a major impact on the lives of patients and their families. This study highlights significant geographical variation in secondary fracture prevention with even the highest performing regions failing the majority of patients despite robust evidence supporting the benefits of diagnosis and treatment.

Introduction The purpose of the study is to describe the geographic variation in anti-osteoporosis drug therapy prescriptions before and after a hip fracture during 1999-2013 in the UK.

Methods We used primary care data (Clinical Practice Research Datalink) to identify patients with a hip fracture and primary care prescriptions of any anti-osteoporosis drugs prior to the index hip fracture and up to 5 years after. Geographic variations in prescribing before and after availability of generic oral bisphosphonates were analysed.
\end{abstract}

A Judge and MK Javaid are joint last authors.

Electronic supplementary material The online version of this article (doi:10.1007/s00198-016-3811-4) contains supplementary material, which is available to authorized users.

M. K. Javaid

kassim.javaid@ndorms.ox.ac.uk

the REFReSH study team

1 NIHR Musculoskeletal Biomedical Research Unit, Nuffield Department of Orthopaedics, Rheumatology and Musculoskeletal Sciences, Nuffield Orthopaedic Centre, University of Oxford, Windmill Road, Oxford OX3 7LD, UK

2 MRC Lifecourse Epidemiology Unit, University of Southampton, Southampton, UK

3 Royal Berkshire NHS Foundation Trust, Reading, UK
Multivariable logistic regression models were adjusted for gender, age and body mass index (BMI).

Results Thirteen thousand sixty-nine patients (76\% female) diagnosed with a hip fracture during 1999-2013 were identified. Eleven per cent had any anti-osteoporosis drug prescription in the 6 months prior to the index hip fracture. In the 0 4 months following a hip fracture, $5 \%$ of patients were prescribed anti-osteoporosis drugs in 1999 , increasing to $51 \%$ in 2011 and then decreasing to $39 \%$ in 2013.

The independent predictors (OR $(95 \% \mathrm{CI})$ ) of treatment initiation included gender (male $0.42(0.36-0.49))$, BMI $(0.98$ per $\mathrm{kg} / \mathrm{m}^{2}$ increase $\left.(0.97-1.00)\right)$ and geographic region (1.29 (0.89-1.87) North East vs. $0.56(0.43-0.73)$ South Central region). Geographic differences in prescribing persisted over the 5-year follow-up. If all patients were treated at the rate of the highest performing region, then nationally, an additional 3214 hip fracture patients would be initiated on therapy every year.

Conclusions Significant geographic differences exist in prescribing of anti-osteoporosis drugs after hip fracture despite adjustment for potential confounders. Further work examining differences in health care provision may inform strategies to improve secondary fracture prevention after hip fracture.

Keywords Epidemiology · Geographic variation · Hip fracture $\cdot$ Osteoporosis $\cdot$ Primary care data $\cdot$ Secondary fracture prevention

\section{Introduction}

Fragility fractures of the hip are associated with significant morbidity, increased risk of subsequent falls and other fractures as well as higher mortality [1-3]. About 87,000 hip fractures occur annually in the UK, mostly in elderly individuals with 
underlying bone fragility as a result of osteoporosis. Almost half of all hip fracture patients have had a prior fracture [2]. The estimated risk of a second hip fracture ranges from 2.3 to $10.6 \%$, with the majority of second hip fractures occurring within a few years after the first [4]. One-year mortality estimates following fracture range from 8.4 to $36 \%$ [2].

Anti-osteoporosis drugs (e.g. bisphosphonates) and interventions to help patients to avoid falls can potentially halve the risk of further hip fractures [5]. Persistence with antiosteoporotic drug therapy is important for reducing the number of secondary fractures, and discontinuing therapy is associated with a $32 \%$ increase in fracture risk [6]. Despite costeffective medicines that reduce re-fracture [7], there has been a failure to translate research evidence and guidance into routine clinical care with reported low rates of prescribing for patients surviving a hip fracture [8]. We have previously demonstrated a significant increase in treatment initiation following the availability of generic bisphosphonates and publication of national guidance for secondary fracture prevention [9].

Geographic variations in health care delivery have been used to inform health care policy [10]. Geographical variation that remains after adjustment for demographic factors is unlikely to be due to differences in disease prevalence or patient preferences. UK health care policy places duties on health services to reduce variations in access to, and outcomes from, health care services for patients, and to assess and report on how well they have fulfilled this duty. The aim of the study was to describe geographic variation in prescription of antiosteoporosis drug therapy before and after a hip fracture during 1999-2013 within the UK.

\section{Methods}

\section{Data sources}

Primary care data from the Clinical Practice Research Datalink (CPRD) were used to identify patients with a hip fracture. The CPRD covers 11.3 million people from 674 UK practices, with a current coverage of approximately $6.9 \%$ of the UK population who are broadly representative of the UK population in terms of age, sex and ethnicity [11]. The Office for National Statistics database on mortality was linked and validated with the data within CPRD. While the data is anonymised at the participant level, geographical information is recorded by dividing the UK into 13 geographic regions.

\section{Study population}

Hip fractures occurring between 1 January 1999 and 30 September 2013 among patients over the age of 60 years were identified using READ codes as defined a priori after consensus by two clinicians experienced in clinical practice and epidemiological research [12]. To ensure that primary not secondary hip fractures had been captured, patients had to have no record of a hip fracture in the 3 years preceding the identified hip fracture.

The treatment outcomes were defined as the proportion of patients who were treated with anti-osteoporosis medications 6 months prior to hip fracture, within 4 months of primary hip fracture and up to 5 years after were calculated for each geographical region. Patients who died or who were lost to follow-up prior to the relevant time periods were not included. Medications classified as 'anti-osteoporosis' included oral bisphosphonates, hormone replacement therapy (HRT), selective oestrogen receptor modulators (SERMS), strontium ranelate, denosumab and teriparatide. Outcomes were also stratified by gender and calendar period of primary hip fracture (1999-2004 vs. 2005-2013), reflecting the availability of generic bisphosphonates and national guidelines for secondary fracture prevention.

The main predictor was geographical region, which is predefined in CPRD, and extracted at the patient level. A priori, we use the region with the largest number of cases as the referent region, the North West. The following potential confounders were also extracted: gender and calendar period of primary hip fracture, body mass index (BMI, $\mathrm{kg} / \mathrm{m}^{2}$ ), socioeconomic status (Index of Multiple Deprivation 2004), Charlson Index of Comorbidity, other specific comorbid conditions, smoking status (current, ex, and non-smoker) and drinking status (current, ex, and non-drinker) and other previous non-hip fractures.

\section{Statistical analysis}

Descriptive statistical techniques were used to present variations in prevalence of prescribing by geographical region combining both incident and prevalent users in pre-defined time periods before and after the index fracture. Multiple imputation using chained equations was used to account for missing data on body mass index, smoking and drinking [13]. Twenty imputed datasets were generated using all potential factors (including the outcome) and estimated parameters were combined using Rubin's rules. Many patients had missing data on Index of Multiple Deprivation (41\%), which was defined as 'missing not at random' because the score can only be calculated for patients in England. This factor was included in a complete case model as a confounder in a sensitivity analysis.

Independent risk factors for prescription with an antiosteoporosis medicine were identified using multivariable logistic regression models. All potential predictors were assessed in univariate models, and then in multivariable models using backward-stepwise selection. A parsimonious multivariable model was identified from the full model using cut-offs of p-entry 0.049 and p-exit 0.10 . Univariate and multivariate models were applied to patients with complete data 
Table 1 Baseline characteristics among primary hip fracture patients within the Clinical Practice Research Datalink during 1999-2013, UK

\begin{tabular}{|c|c|c|c|}
\hline \multicolumn{2}{|l|}{ Characteristic } & \multirow{2}{*}{$\begin{array}{l}\text { Number } \\
5738\end{array}$} & \multirow{2}{*}{$\begin{array}{l}\text { Percentage } \\
(\%)\end{array}$} \\
\hline Calendar period & 1999-2004 & & \\
\hline & $2005-2013$ & 7331 & 56 \\
\hline \multirow[t]{2}{*}{ Gender } & Female & 9995 & 76 \\
\hline & Male & 3074 & 24 \\
\hline \multirow[t]{4}{*}{ Age at hip fracture } & $60-69$ years & 1199 & 9 \\
\hline & 70-79 years & 3291 & 25 \\
\hline & $80-89$ years & 6095 & 47 \\
\hline & $\geq 90$ years & 2484 & 19 \\
\hline \multirow{6}{*}{$\begin{array}{l}\text { Body mass index } \\
\qquad\left(\mathrm{kg} / \mathrm{m}^{2}\right)\end{array}$} & $<18.5$ & 864 & 7 \\
\hline & $18.5-24.9$ & 5352 & 41 \\
\hline & $25.0-29.9$ & 3169 & 24 \\
\hline & $30-34.9$ & 944 & 7 \\
\hline & $\geq 35$ & 236 & 2 \\
\hline & Missing & 2504 & 19 \\
\hline \multirow{6}{*}{$\begin{array}{l}\text { Index of Multiple } \\
\text { Deprivation } \\
\text { (quintile of } \\
\text { deprivation) }\end{array}$} & Affluent & 1694 & 13 \\
\hline & 2 & 1812 & 14 \\
\hline & 3 & 1491 & 11 \\
\hline & 4 & 1550 & 12 \\
\hline & Deprived & 1129 & 9 \\
\hline & Missing & 5393 & 41 \\
\hline \multirow[t]{4}{*}{ Smoking } & No & 7343 & 56 \\
\hline & Yes & 1697 & 13 \\
\hline & Ex & 3021 & 23 \\
\hline & Missing & 1008 & 8 \\
\hline \multirow[t]{4}{*}{ Drinking } & Yes & 7261 & 56 \\
\hline & No & 3391 & 26 \\
\hline & Ex & 349 & 3 \\
\hline & Missing & 2068 & 16 \\
\hline \multirow{4}{*}{$\begin{array}{l}\text { Charlson } \\
\text { co-morbidity } \\
\text { index }\end{array}$} & 0 & 6737 & 52 \\
\hline & 1 & 2250 & 17 \\
\hline & 2 & 1979 & 15 \\
\hline & $\geq 3$ & 2103 & 16 \\
\hline \multirow[t]{11}{*}{ Region } & East Midlands & 783 & 6 \\
\hline & East of England & 1363 & 10 \\
\hline & London & 977 & 7 \\
\hline & North East & 338 & 3 \\
\hline & North West & 1921 & 15 \\
\hline & Northern Ireland & 678 & 5 \\
\hline & Scotland & 681 & 5 \\
\hline & South Central & 1031 & 8 \\
\hline & South East Coast & 1277 & 10 \\
\hline & South West & 1323 & 10 \\
\hline & Wales & 922 & 7 \\
\hline
\end{tabular}

Table 1 (continued)

\begin{tabular}{|c|c|c|c|}
\hline Characteristic & & Number & $\begin{array}{l}\text { Percentage } \\
(\%)\end{array}$ \\
\hline & West Midlands & 1104 & 8 \\
\hline & Yorkshire and the Humber & 671 & 5 \\
\hline \multirow{10}{*}{$\begin{array}{l}\text { Co-morbid } \\
\text { conditions }\end{array}$} & Asthma & 1796 & 14 \\
\hline & Malabsorption Syndromes & 21 & 0 \\
\hline & $\begin{array}{l}\text { Inflammatory bowel } \\
\text { disease }\end{array}$ & 189 & 1 \\
\hline & Hypertension & 6568 & 50 \\
\hline & Hyperlipidaemia & 1884 & 14 \\
\hline & Ischemic heart disease & 2816 & 22 \\
\hline & Cerebro-vascular disease & 1453 & 11 \\
\hline & $\begin{array}{l}\text { Chronic obstructive } \\
\text { pulmonary disorder }\end{array}$ & 1214 & 9 \\
\hline & Chronic renal failure & 712 & 5 \\
\hline & Cancer & 2674 & 20 \\
\hline \multirow[t]{6}{*}{ Previous fractures } & Previous spinal fracture & 178 & 1 \\
\hline & Previous wrist fracture & 1270 & 10 \\
\hline & Previous humerus fracture & 67 & 1 \\
\hline & Previous pelvis fracture & 187 & 1 \\
\hline & Previous rib fracture & 321 & 2 \\
\hline & $\begin{array}{l}\text { Previous other non-hip } \\
\text { fracture }\end{array}$ & 699 & 5 \\
\hline $\begin{array}{l}\text { Previous joint } \\
\text { replacement }\end{array}$ & & 1143 & 9 \\
\hline \multirow[t]{2}{*}{ Mortality } & $0-4$ months & 1854 & 14 \\
\hline & 5-12 months & 1061 & 8 \\
\hline
\end{tabular}

( $N=6019)$ and the imputed data for all patients $(N=13,069)$. A sensitivity analysis was conducted on the imputed datasets for patients who had data on Index of Multiple Deprivation ( $N=7676)$, which resulted in similar odds ratios as those for the imputed data for all patients.

An additional sensitivity analysis was conducted using Fine and Gray survival regression models to take into account the competing risk of mortality [14]. Patients were censored at the date of death or at the end of follow-up. All analyses were performed using STATA v14.1.

\section{Results}

A cohort of 13,069 patients diagnosed with a primary hip fracture during 1999-2013 was identified in CPRD; their descriptive factors are described in Table 1. Following the index hip fracture, mortality was high with $14 \%$ of patients dying within 4 months and an additional $8 \%$ dying within a year.

Overall, rates of prescribing of anti-osteoporosis drugs in the 6 months prior to index hip fracture were very low (11\%) with no significant geographical variation (Fig. 1). 
Fig. 1 Percentage of patients on any anti-osteoporosis medicine 6 months prior to primary hip fracture and $0-4$ months following primary hip fracture by geographical region within the Clinical Practice Research Datalink, 1999-2013, UK. Bars show the percentage of patients prescribed any anti-osteoporosis medication in the 6 months prior to and within 4 months post index hip fracture.

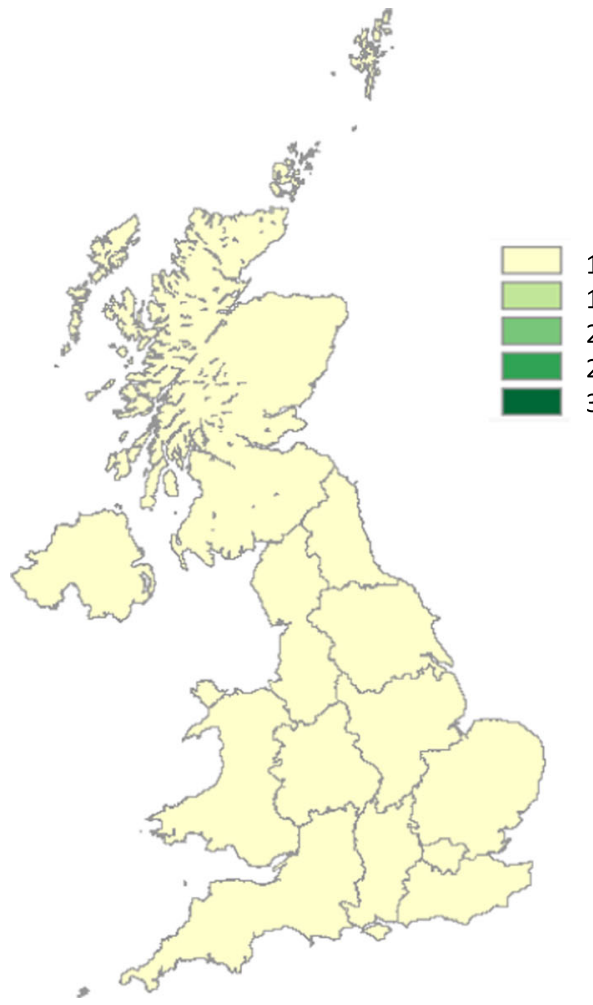

Prescriptions 0-4 months post

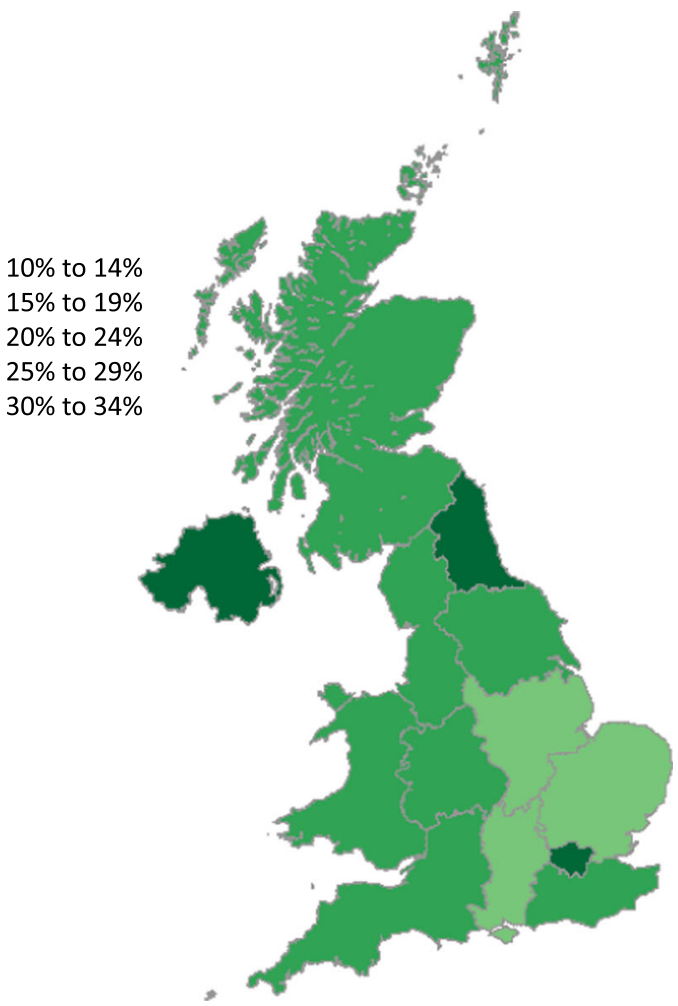

Geographic differences in prior prescription did not predict prescribing patterns following hip fracture.

Nationally, in the $0-4$ months following a hip fracture, $5 \%$ of patients were prescribed an anti-osteoporosis drug in 1999, which increased to $51 \%$ in $2011(p<0.001)$ and significantly decreased to $39 \%$ in $2013(p<0.001)$.

During the entire study period (1999-2013), independent predictors of treatment initiation included men $(\mathrm{OR}=0.43$ $95 \%$ CI $0.39-0.49, p=<0.001)$, increasing BMI $(\mathrm{OR}=0.9895 \%$ CI $0.97-0.99, p=0.002)$ and region $(\mathrm{OR}=1.4495 \%$ CI $1.10-1.88, p=0.008$ North East vs. $\mathrm{OR}=0.7795 \%$ CI 0.64-0.93, $p=0.006$ South Central, with North West region as reference category) (Table 2). If all patients were treated at the rate of the highest performing region, then nationally 3214 additional hip fracture patients would be initiated on therapy every year.

There was a significant interaction between geographic region and calendar period of hip fracture $(p=0.0047)$ (Table 3$)$. During 1999-2004, overall $10 \%$ of patients with a primary hip fracture were prescribed anti-osteoporosis drugs within 4 months with little variation by geographic region (Fig. 2a). However during 2005-2013, this increased to $40 \%$ with marked variations between regions $(50 \%$ of the patients in the North East compared with $34 \%$ of patients in the South Central region) (Fig. 2b). The percentage of patients on antiosteoporosis drugs both in the $0-6$ months pre and $0-4$ post hip fracture increased from 59 to $75 \%$ from 1999-2004 to
2005-2013. Further, the percentage of patients who were on anti-osteoporosis drugs before their hip fracture and then stopped immediately aftewarrds reduced from 41 to $25 \%$ between these time periods.

Following an index hip fracture, there was a significant decline in prescription rates such that by 5 years only $15 \%$ were on any anti-osteoporosis therapy (Fig. 2a, b). Regional differences in prescribing persisted over the 5-year follow-up; $10 \%$ of patients were on therapy at 5 years in the South Central region in contrast with those in the North East (25\%) and in Northern Ireland (27 \%) during 2005-2013. While there was a significant difference in medication initiation by calendar year, the overall prescribing rates at 5 years were similar between 1999-2004 and 2005-2013 (15.9 vs. $15.8 \%$, respectively). Models adjusting for the competing risk of death produced similar findings (see supplementary table).

\section{Discussion}

\section{Summary of key findings}

This study has confirmed significant geographic variation in initiation of anti-osteoporosis medication after hip fracture in the UK. However, even the best performing geographical region had lower initiation rates than anticipated and longerterm prescribing of therapy remained low. 
Table 2 Estimated odds ratios (OR) of patients receiving a prescription within 4 months of primary hip fracture within the Clinical Practice Research Datalink, 1999-2013, UK

\begin{tabular}{|c|c|c|c|c|c|c|c|c|c|c|c|c|c|c|}
\hline \multirow[t]{3}{*}{ Characteristic } & & \multicolumn{8}{|c|}{ Complete case analysis $N=6019$} & \multicolumn{5}{|c|}{$\begin{array}{l}\text { Multiple imputed data on BMI, smoking } \\
\text { and drinking } N=13,069\end{array}$} \\
\hline & & \multirow[t]{2}{*}{ Number } & \multirow[t]{2}{*}{$\%$} & \multicolumn{2}{|c|}{ Univariate } & \multicolumn{2}{|c|}{ Multivariate } & \multirow[t]{2}{*}{$\begin{array}{l}p \\
\text { value }\end{array}$} & \multirow[t]{2}{*}{$\%$} & \multicolumn{2}{|c|}{$\begin{array}{l}\text { Univariate } \\
N=13,069\end{array}$} & \multicolumn{2}{|c|}{ Multivariate } & \multirow[t]{2}{*}{$\begin{array}{l}p \\
\text { value }\end{array}$} \\
\hline & & & & OR & $95 \%$ CI & OR & $95 \%$ CI & & & OR & $95 \% \mathrm{CI}$ & OR & $95 \% \mathrm{CI}$ & \\
\hline \multirow[t]{13}{*}{ Region (ref: North West) } & East Midlands & 256 & 4 & 0.94 & $0.70-1.26$ & 1.00 & $0.73-1.37$ & 0.990 & 6 & 0.76 & $0.62-0.92$ & 0.81 & $0.66-1.00$ & 0.053 \\
\hline & East of England & 854 & 14 & 0.93 & $0.77-1.13$ & 0.86 & $0.70-1.07$ & 0.179 & 10 & 0.83 & $0.71-0.97$ & 0.89 & $0.75-1.06$ & 0.203 \\
\hline & London & 476 & 8 & 0.95 & $0.75-1.19$ & 0.92 & $0.71-1.18$ & 0.496 & 7 & 1.08 & $0.91-1.28$ & 1.08 & $0.90-1.30$ & 0.426 \\
\hline & North East & 153 & 3 & 1.33 & $0.94-1.89$ & 1.26 & $0.87-1.84$ & 0.224 & 3 & 1.34 & $1.04-1.71$ & 1.44 & $1.10-1.88$ & 0.008 \\
\hline & North West & 1183 & 20 & 1.00 & & 1.00 & & & 15 & 1.00 & & 1.00 & & \\
\hline & Northern Ireland & & & & & & & & 5 & 1.19 & $0.98-1.44$ & 1.18 & $0.96-1.45$ & 0.125 \\
\hline & Scotland & & & & & & & & 5 & 0.94 & $0.77-1.14$ & 0.91 & $0.74-1.12$ & 0.381 \\
\hline & South Central & 463 & 8 & 0.69 & $0.54-0.88$ & 0.56 & $0.42-0.73$ & $<0.001$ & 8 & 0.82 & $0.69-0.97$ & 0.77 & $0.64-0.93$ & 0.006 \\
\hline & South East Coast & 598 & 10 & 0.87 & $0.70-1.07$ & 0.82 & $0.64-1.04$ & 0.098 & 10 & 0.98 & $0.84-1.15$ & 0.99 & $0.84-1.18$ & 0.926 \\
\hline & South West & 916 & 15 & 0.93 & $0.77-1.12$ & 0.91 & $0.74-1.11$ & 0.353 & 10 & 0.90 & $0.76-1.05$ & 0.93 & $0.78-1.10$ & 0.395 \\
\hline & Wales & & & & & & & & 7 & 0.96 & $0.81-1.15$ & 0.96 & $0.79-1.16$ & 0.665 \\
\hline & West Midlands & 746 & 12 & 0.90 & $0.74-1.10$ & 0.88 & $0.70-1.09$ & 0.228 & 8 & 0.90 & $0.76-1.07$ & 0.91 & $0.76-1.09$ & 0.298 \\
\hline & $\begin{array}{l}\text { Yorkshire and the } \\
\text { Humber }\end{array}$ & 374 & 6 & 1.07 & $0.83-1.37$ & 1.07 & $0.82-1.40$ & 0.628 & 5 & 0.93 & $0.76-1.13$ & 1.06 & $0.86-1.32$ & 0.580 \\
\hline \multirow{2}{*}{$\begin{array}{l}\text { Calendar period of hip } \\
\text { fracture }\end{array}$} & 1999-2004 & 2170 & 36 & 1.00 & & 1.00 & & & 44 & 1.00 & & 1.00 & & \\
\hline & $2005-2013$ & 3849 & 64 & 5.52 & $4.76-6.41$ & 6.00 & $5.15-7.00$ & $<0.001$ & 56 & 5.67 & $5.14-6.25$ & 6.14 & $5.55-6.79$ & $<0.001$ \\
\hline \multirow[t]{2}{*}{ Gender } & Female & 4547 & 76 & 1.00 & & 1.00 & & & 76 & 1.00 & & 1.00 & & \\
\hline & Male & 1472 & 24 & 0.46 & $0.40-0.53$ & 0.42 & $0.36-0.50$ & $<0.001$ & 24 & 0.50 & $0.45-0.55$ & 0.43 & $0.39-0.49$ & $<0.001$ \\
\hline \multirow[t]{4}{*}{ Age at hip fracture (years) } & $60-69$ years & 537 & 9 & 0.76 & $0.62-0.93$ & 0.86 & $0.69-1.08$ & 0.206 & 9 & 0.85 & $0.74-0.98$ & 0.95 & $0.81-1.11$ & 0.520 \\
\hline & 70-79 years & 1567 & 26 & 0.89 & $0.78-1.01$ & 1.01 & $0.88-1.17$ & 0.859 & 25 & 0.97 & $0.89-1.07$ & 1.11 & $1.00-1.24$ & 0.043 \\
\hline & $80-89$ years & 2858 & 47 & 1.00 & & 1.00 & & & 47 & 1.00 & & 1.00 & & \\
\hline & $>90$ years & 1057 & 18 & 0.71 & $0.60-0.83$ & 0.59 & $0.50-0.70$ & $<0.001$ & 19 & 0.70 & $0.63-0.78$ & 0.61 & $0.54-0.69$ & $<0.001$ \\
\hline \multicolumn{2}{|c|}{ Body mass index $\left(\mathrm{kg} / \mathrm{m}^{2}\right)$ prior to hip fracture } & & & 0.98 & $0.97-0.99$ & 0.98 & $0.97-0.99$ & 0.005 & 100 & 0.99 & $0.98-1.00$ & 0.98 & $0.97-0.99$ & 0.002 \\
\hline \multicolumn{2}{|c|}{$\begin{array}{l}\text { Index of Multiple Deprivation quintile } \\
\quad(\text { ref = affluent) }\end{array}$} & & & 0.96 & $0.92-0.99$ & 0.93 & $0.89-0.97$ & 0.003 & & & & & & \\
\hline \multirow[t]{3}{*}{ Smoking } & Non-smoker & 3614 & 60 & 1.00 & & 1.00 & & & 61 & 1.00 & & 1.00 & & \\
\hline & Current & 762 & 13 & 0.77 & $0.65-0.93$ & 0.89 & $0.73-1.09$ & 0.260 & 14 & 0.83 & $0.74-0.94$ & 0.92 & $0.80-1.06$ & 0.236 \\
\hline & Ex-smoker & 1643 & 27 & 1.00 & $0.88-1.13$ & 1.00 & $0.87-1.16$ & 0.970 & 25 & 1.14 & $1.04-1.25$ & 1.03 & $0.93-1.14$ & 0.573 \\
\hline \multirow[t]{3}{*}{ Drinking } & Current & 4135 & 69 & 1.00 & & 1.00 & & & 66 & 1.00 & & 1.00 & & \\
\hline & Non-drinker & 1683 & 28 & 1.04 & $0.92-1.18$ & 0.95 & $0.83-1.09$ & 0.494 & 31 & 1.01 & $0.92-1.10$ & 0.92 & $0.83-1.02$ & 0.121 \\
\hline & Ex-drinker & 201 & 3 & 0.93 & $0.68-1.28$ & 0.81 & $0.58-1.14$ & 0.224 & 3 & 0.99 & $0.78-1.27$ & 0.77 & $0.60-1.00$ & 0.048 \\
\hline $\begin{array}{l}\text { Charlson co-morbidity in- } \\
\quad \operatorname{dex}(\text { ref }=0)\end{array}$ & & & & 0.99 & $0.96-1.02$ & 0.95 & $0.92-0.99$ & 0.004 & 100 & 1.01 & $0.98-1.03$ & 0.95 & $0.93-0.98$ & $<0.001$ \\
\hline Co-morbid conditions & Hypertension & 3337 & 55 & 1.38 & $1.23-1.54$ & 1.17 & $1.03-1.32$ & 0.016 & 50 & 1.49 & $1.37-1.61$ & 1.20 & $1.10-1.31$ & $<0.001$ \\
\hline \multirow[t]{3}{*}{ Previous fractures } & Spine fracture & 106 & 2 & 1.89 & $1.28-2.78$ & 1.83 & $1.20-2.79$ & 0.005 & 1 & 2.32 & $1.72-3.13$ & 2.15 & $1.55-2.98$ & $<0.001$ \\
\hline & Humerus fracture & 29 & $<1$ & 2.19 & $1.06-4.55$ & 2.90 & $1.32-6.37$ & 0.008 & 1 & 1.98 & $1.22-3.22$ & 2.15 & $1.28-3.64$ & 0.004 \\
\hline & $\begin{array}{l}\text { Other non-hip } \\
\text { fracture }\end{array}$ & 350 & 6 & 1.38 & $1.10-1.72$ & 1.41 & $1.10-1.80$ & 0.006 & 5 & 1.44 & $1.22-1.69$ & 1.36 & $1.14-1.62$ & 0.001 \\
\hline
\end{tabular}

Odds ratios (OR) shown for complete case and multiply imputed univariate and mutually adjusted Cox models.

\section{Geographical variation of care}

Geographical variation in health care use has been used for many decades to highlight areas for further investigation and potentially significant change in routine clinical care. Historically, the description of an up to eightfold difference in tonsillectomy between comparable towns within England and USA [15] led to dis-investment in tonsillectomy and subsequent clinical trials to identify the subgroups who do benefit. More recent reviews of studies of geographical variation have confirmed its value to highlight a potential priorities for evidence synthesis and/or dissemination to inform local commissioning with the aims of standardizing current practice around current best evidence [10]. While typically applied to high volume procedures, geographical variation in care has been shown to also apply where there is underuse of healthcare [16]. Variation in care has been identified in a number of disease areas including radiotherapy for cancer [17], ischaemic heart disease [18] but not childhood asthma [19].

The major drivers of geographical variation in health care delivery are (a) difference in physicians' ability to diagnose patients and (b) difference in physicians' belief 
Table 3 Estimated odds ratios (OR) of patients receiving a prescription within 4 months of primary hip fracture by region and calendar period of diagnosis within the Clinical Practice Research Datalink, 1999-2013, UK

\begin{tabular}{|c|c|c|c|c|c|c|}
\hline \multirow[t]{2}{*}{ Region } & \multicolumn{3}{|c|}{ 1999-2004 } & \multicolumn{3}{|c|}{ 2005-2013 } \\
\hline & OR & $95 \% \mathrm{CI}$ & $p$ value & OR & $95 \% \mathrm{CI}$ & $p$ value \\
\hline East Midlands & 0.87 & $0.56-1.33$ & 0.513 & 0.79 & $0.62-1.01$ & 0.057 \\
\hline East of England & 1.42 & $1.02-1.97$ & 0.037 & 0.76 & $0.62-0.92$ & 0.006 \\
\hline London & 1.09 & $0.74-1.60$ & 0.665 & 1.07 & $0.87-1.33$ & 0.51 \\
\hline North East & 1.40 & $0.82-2.38$ & 0.221 & 1.48 & $1.08-2.03$ & 0.015 \\
\hline North West (Referent) & 1.00 & & & 1.00 & & \\
\hline Northern Ireland & 1.37 & $0.90-2.11$ & 0.144 & 1.14 & $0.90-1.44$ & 0.284 \\
\hline Scotland & 1.47 & $0.98-2.22$ & 0.062 & 0.77 & $0.60-0.98$ & 0.033 \\
\hline South Central & 0.92 & $0.62-1.38$ & 0.694 & 0.73 & $0.59-0.90$ & 0.004 \\
\hline South East Coast & 0.94 & $0.65-1.37$ & 0.748 & 1.01 & $0.83-1.23$ & 0.922 \\
\hline South West & 0.93 & $0.65-1.34$ & 0.707 & 0.93 & $0.77-1.14$ & 0.493 \\
\hline Wales & 0.65 & $0.42-1.02$ & 0.062 & 1.04 & $0.84-1.29$ & 0.700 \\
\hline West Midlands & 0.74 & $0.49-1.13$ & 0.158 & 0.95 & $0.78-1.17$ & 0.634 \\
\hline Yorkshire and the Humber & 1.06 & $0.69-1.62$ & 0.790 & 1.07 & $0.83-1.38$ & 0.599 \\
\hline
\end{tabular}

Univariate comparison of prescription of anti-osteoporosis drugs in 1999-2004 vs. 2005-2013 by region. in the benefits of the intervention [20]. These are underpinned by variation in technology diffusion [21] and gaps in the clinical knowledge of clinicians or how they apply their knowledge [22]. In case of the tonsillectomy in the early twentieth century, the geographical variation in physicians' diagnosis and treatment was due to the lack of trial evidence for the intervention. In contrast, the observed variation in secondary fracture prevention is not due to a lack of robust evidence for how to diagnose high-risk patients or the lack of evidence for the treatment benefit and likely reflects inadequate technology diffusion.

A number of tools have been validated to identify and diagnose patients at high risk that would benefit from pharmacotherapy such as FRAX [23] and Qfracture [24]. The National Osteoporosis Guidance Group recommendations deliver treatment thresholds within FRAX as a decision aid to support physicians in the diagnosis of patients who would benefit from therapy [25]. The FRAX tool has now been tested in a large-scale randomized controlled trial and demonstrated an impressive $24 \%$ reduction in hip fracture associated with an $80 \%$ prescription rate in those identified at high risk vs. $12 \%$ in the control group [26]. The lower treatment rates and lack of difference in the pre-fracture period suggests (a) selection and maintainance of anti-osteoporosis prescriptions in highrisk patients who go on to fracture are poor in primary care and (b) post-fracture variation in secondary fracture prevention most likely reflects the variable presence of fracture liaison services within the UK [27].

Another issue is the belief of benefit of secondary fracture prevention among the wider health care community and policy makers. Despite a number of trials demonstrating fracture reduction from 20 to $70 \%$ using antiosteoporosis medications [5] and the cost-effectiveness of these interventions [28], secondary fracture prevention in the UK remains poor with less than a third of the expected number of patients treated for secondary fracture prevention included in the UK Quality Outcome Framework in 2013/14, a national re-imbursement scheme for primary care [29]. Further, recently published perspectives in general medical journals, based on opinion and not the balance of published literature [30], have questioned the effectiveness of pharmacotherapy for secondary fracture prevention causing confusion over the benefits of secondary prevention, denying high-risk patients anti-osteoporosis therapy and leading to avoidable fragility fractures to the detriment of patients, their family, carers and the society as a whole.

\section{Medication persistence}

While in the randomized controlled trials used to register agents, persistence with therapy was over $90 \%$ [31], real world data has consistently described poor persistence in the real world setting with rates of primary non-adherence of up to $30 \%$ [32] and secondary non-adherence between 30 and $50 \%$ at 1 year [33]. Persistance has been reported as higher in the 1 year after fragility fracture but still low in those aged 80 and over [34]. Non-adherence to antiosteoporosis medication is associated with a $30-40 \%$ increase in the risk of fracture [6]. In this study, the geographic variation in medication prescriptions persisted from initiation to 5 years after the index fracture. However, the higher rates of medication initiation after 2005 did not translate to higher rates of prescriptions at 5 years across geographical regions. The poor adherence to anti-osteoporosis therapies is well known and monitoring has been recognized as one of the essential components for a secondary fracture prevention care pathway to be effective [35]. The most efficient methods for monitoring have yet to be determined. The major reasons for lack 
a
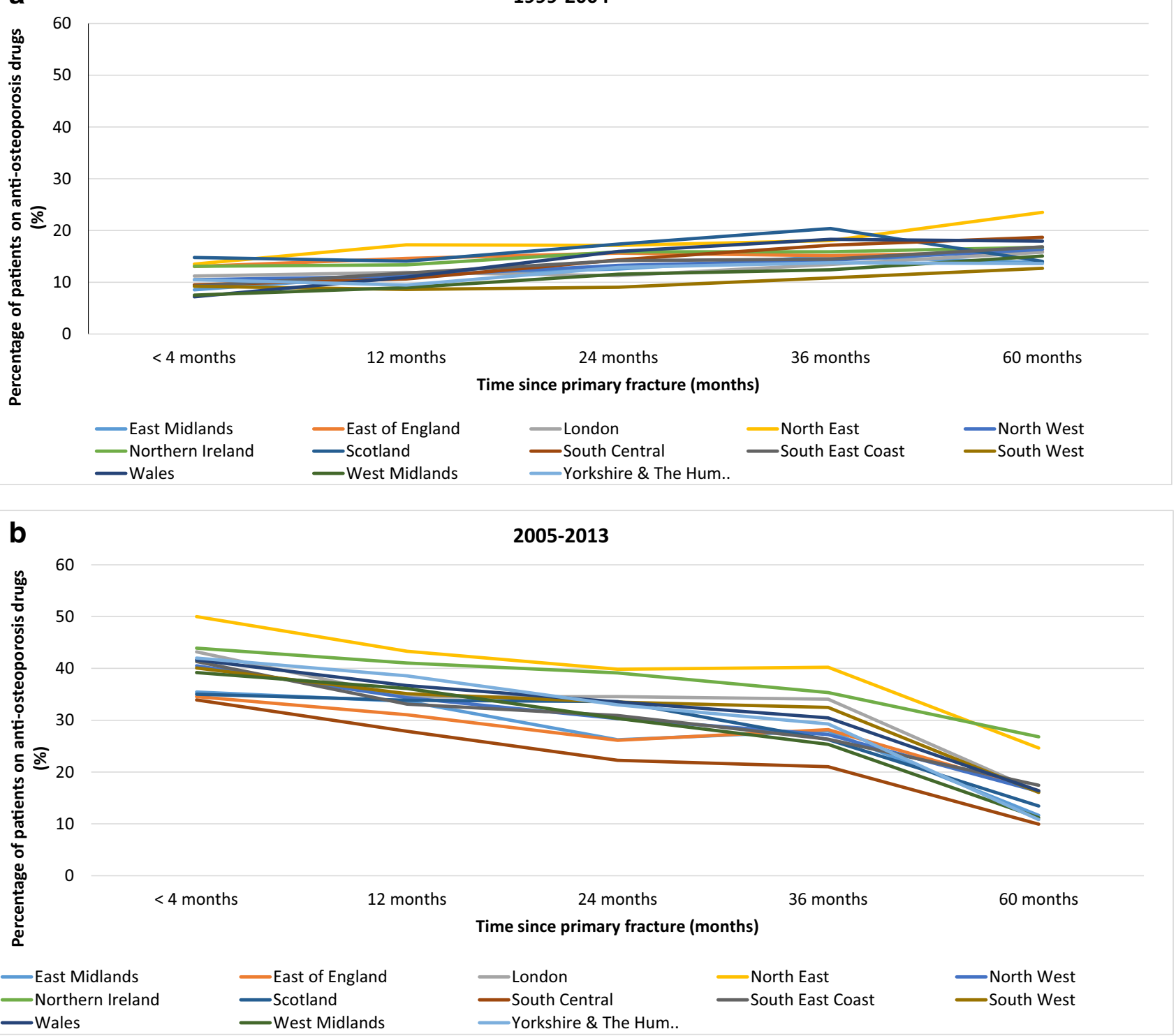

Fig. 2 Prescription rates of any anti-osteoporosis medication after primary hip fracture by geographical region during 1999-2004 (2a) and during 2005-2013 (2b) within the Clinical Practice Research Datalink,

of persistence with oral bisphosphonates, the first-line anti-osteoporosis therapy used in most cases, include patient characteristics (experiencing side effects, insufficient motivation, lack of perceived benefit and the complex administration [36]) and physician characteristics (overestimation of patient adherence [37] and physician misinformation [36]).

Improving medication persistence to anti-osteoporosis therapy is challenging. A number of strategies such as providing reminders [38], motivational telephone interventions [39], personal training using telephone calls and group meetings [40] have been tested and do not improve treatment persistence to anti-osteoporosis. However, the longer treatment interval and simpler
UK. This figure shows for each time period, the proportion of patients alive and followed up within CPRD receiving a prescription of antiosteoporosis medication.

administration regimes with denosumab have been shown to increase 12-month persistence rates to over $80 \%$ in routine clinical practice [41, 42].

\section{Secondary fracture prevention care gap and Fracture Liaison Services}

International bodies such as the ASBMR and IOF [43, 44] have published guidelines on service models to improve secondary fracture prevention to reduce subsequent fractures [45]. These recommendations recommend that Fracture Liaison Services be created to close the care gap in secondary fracture prevention. However, in the UK, less than $40 \%$ of hospitals in England had 
established such a service by 2010 and there is marked variability in service delivery with more than $50 \%$ of services identifying less than $50 \%$ of their expected fragility fracture caseload annually [27]. Published criteria and standards are now available as part of an improvement programme to improve the quality of Fracture Liaison Services and ensure they are both effective and efficient [46].

\section{Strengths and limitations}

This is a large study using real world data that used validated methods to ascertain the primary fracture. Two statistical methods were used to analyse the data given we did not know how mortality may differ in the data. Given competing risk methods such as Fine and Gray need to be used if the mortality rates differ between exposure groups, and mortality after hip fracture did not vary by region, both Cox and Fine and Gray gave similar findings. Regional denominators were not available and so the proportion of patients presenting with a hip fracture per region is not known. While primary care data in the UK captures prescribing of oral anti-osteoporosis medication, the prescribing of parenteral therapies such as teriparatide, zoledronate and denosumab is likely underestimated, as a proportion will be prescribed in the secondary care setting with inconsistent recording in the primary care record. This may account for some of the differences in prescribing rates between 2011 and 2013. While we did not have access to dispensing data and, from other sources, the rates of primary non-adherence are up to $30 \%$ [32]. In the UK if a patient does not pick up their prescription then the pharmacy feeds this back to the primary care physician and future scripts are not issued and these patients would be identified as non-adherent.

\section{Conclusions}

Fragility fractures of the hip have a major impact on the lives of patients and their families as well as to health care and society. This study highlights significant geographical variation in secondary fracture prevention with even the highest performing regions failing the majority of patients despite robust evidence supporting the benefits of diagnosis and treatment. Further health services research including the use of guidelines and decision aids are needed to close this care gap and prevent avoidable fragility fractures and their clinical and economic sequelae.

Acknowledgments The ReFRESH study group consists of Dr. Andrew David Judge, Dr. Muhammad Kassim Javaid, Professor Nigel Arden, Professor Cyrus Cooper, Professor Andrew Farmer, Dr. Daniel Prieto-
Alhambra, Dr. Jose Leal, Professor Michael Goldacre, Professor Alastair Gray, Dr. Janet Lippett, Dr. Rachael Gooberman-Hill and Laura Graham.

\section{Compliance with ethical standards}

Conflicts of interest $\mathrm{AS}, \mathrm{SH}$ and $\mathrm{AD}$ have no competing financial interests relevant to the submitted work. DPA, JL, CC, MKJ and AJ received grants from NIHR HS\&DR during the conduct of the study. Outside the submitted work, MKJ reports personal fees from Lilly UK, Amgen, Sevier, Merck, Medtronic, Internis, Consilient Health, Stirling Anglia, Mereo Biopharma and Optasia. He serves on the Scientific Committee of the National Osteoporosis Society and International Osteoporosis Foundation; DPA received grants from Bioiberica S.A. and Amgen Spain S.A.; CC received personal fees from Servier, Amgen, Eli Lilly, Merck, Medtronic and Novartis. AJ has received consultancy, lecture fees and honoraria from Servier, UK Renal Registry, Oxford Craniofacial Unit, IDIAP Jordi Gol, Freshfields Bruckhaus Deringer, has held advisory board positions (which involved receipt of fees) from Anthera Pharmaceuticals, INC., and received research sponsorship from ROCHE.

Role of the funding source This work was supported by the National Institutes of Health and Research (NIHR) Health Services and Delivery Research programme HS\&DR) (project number 11/1023/01); and from the Oxford NIHR Musculoskeletal Biomedical Research Unit, Nuffield Orthopaedic Centre, University of Oxford. The views and opinions expressed therein are those of the authors and do not necessarily reflect those of the HS\&DR programme, NIHR, NHS or the Department of Health. This study is based in part on data from the Clinical Practice Research Datalink obtained under licence from the UK Medicines and Healthcare products Regulatory Agency. The funding source had no role in the design and conduct of the study, in the collection, analysis and interpretation of the data, or in the preparation, review or approval of the manuscript.

\section{References}

1. Abrahamsen B, van Staa T, Ariely R, Olson M, Cooper C (2009) Excess mortality following hip fracture: a systematic epidemiological review. Osteoporos Int 20:1633-1650

2. Cooper C, Mitchell P, Kanis JA (2011) Breaking the fragility fracture cycle. Osteoporos Int 22:2049-2050

3. Johnell O, Kanis JA, Oden A, Sernbo I, Redlund-Johnell I, Petterson C, De Laet C, Jonsson B (2004) Fracture risk following an osteoporotic fracture. Osteoporos Int 15:175-179

4. Melton LJ 3rd, Kearns AE, Atkinson EJ, Bolander ME, Achenbach SJ, Huddleston JM, Therneau TM, Leibson CL (2009) Secular trends in hip fracture incidence and recurrence. Osteoporos Int 20 : 687-694

5. Freemantle N, Cooper C, Diez-Perez A, Gitlin M, Radcliffe H, Shepherd S, Roux C (2013) Results of indirect and mixed treatment comparison of fracture efficacy for osteoporosis treatments: a metaanalysis. Osteoporos Int 24:209-217

6. Ross S, Samuels E, Gairy K, Iqbal S, Badamgarav E, Siris E (2011) A meta-analysis of osteoporotic fracture risk with medication nonadherence. Value Health 14:571-581

7. NICE (2008) Alendronate, etidronate, risedronate, raloxifene, strontium ranelate and teriparatide for the secondary prevention of 
osteoporotic fragility fractures in postmenopausal women. NICE technology appraisal guidance 161

8. Solomon DH, Johnston SS, Boytsov NN, McMorrow D, Lane JM, Krohn KD (2014) Osteoporosis Medication Use after Hip Fracture in U.S. Patients between 2002 and 2011. J Bone Miner Res

9. Hawley S, Leal J, Delmestri A, Prieto-Alhambra D, Arden NK, Cooper C, Javaid MK, Judge A (2016) Refresh study group AntiOsteoporosis medication prescriptions and incidence of subsequent fracture among primary hip fracture patients in England and Wales: An Interrupted Time-Series Analysis. doi:10.1002/jbmr.2882.

10. Hollingworth W, Rooshenas L, Busby J et al (2015) Using clinical practice variations as a method for commissioners and clinicians to identify and prioritise opportunities for disinvestment in health care: a cross-sectional study, systematic reviews and qualitative study. Health Services and Delivery Research 3:1-172

11. Herrett E, Gallagher A, Bhaskaran K, Forbes H, Mathur R, van Staa T, Smeeth L (2015) Data resource profile: clinical practice research datalink (CPRD). Int J Epidemiol 44:827-836

12. Hawley S, Javaid MK, Prieto-Alhambra D, Lippett J, Sheard S, Arden NK, Cooper C, Judge A (2016) Clinical effectiveness of orthogeriatric and fracture liaison service models of care for hip fracture patients: population-based longitudinal study. Age Ageing 45:236-242

13. White IR, Royston P, Wood AM (2011) Multiple imputation using chained equations: issues and guidance for practice. Stat Med 30: 377-399

14. Fine JPG, Gray RJ (1999) A proportional hazards model for the subdistribution of a competing risk. J Am Stat Assoc 94:496-509

15. Glover JA (1938) The incidence of tonsillectomy in school children: (section of epidemiology and state medicine). Proc R Soc Med 31:1219-1236

16. Sinner MF, Piccini JP, Greiner MA, Walkey AJ, Wallace ER, Heckbert SR, Benjamin EJ, Curtis LH (2015) Geographic variation in the use of catheter ablation for atrial fibrillation among Medicare beneficiaries. Am Heart J 169:775-782 e772

17. Williams MV, Drinkwater KJ (2009) Geographical variation in radiotherapy services across the UK in 2007 and the effect of deprivation. Clin Oncol (R Coll Radiol) 21:431-440

18. Lawlor DA, Bedford C, Taylor M, Ebrahim S (2003) Geographical variation in cardiovascular disease, risk factors, and their control in older women: British Women's Heart and Health Study. J Epidemiol Community Health 57:134-140

19. Kaur B, Anderson HR, Austin J, Burr M, Harkins LS, Strachan DP, Warner JO (1998) Prevalence of asthma symptoms, diagnosis, and treatment in 12-14 year old children across Great Britain (international study of asthma and allergies in childhood, ISAAC UK). BMJ 316:118-124

20. Wennberg JE, Barnes BA, Zubkoff M (1982) Professional uncertainty and the problem of supplier-induced demand. Soc Sci Med $16: 811-824$

21. Skinner J, Staiger D (2015) Technology diffusion and productivity growth in health care. Rev Econ Stat 97:951-964

22. Reames BN, Shubeck SP, Birkmeyer JD (2014) Strategies for reducing regional variation in the use of surgery: a systematic review. Ann Surg 259:616-627

23. Kanis JA, Johnell O, Oden A, Johansson H, McCloskey E (2008) FRAX and the assessment of fracture probability in men and women from the UK. Osteoporosis international: a journal established as result of cooperation between the European Foundation for Osteoporosis and the National Osteoporosis Foundation of the USA 19:385-397

24. Hippisley-Cox J, Coupland C (2009) Predicting risk of osteoporotic fracture in men and women in England and Wales: prospective derivation and validation of QFractureScores. BMJ 339:b4229

25. Kanis JA, McCloskey EV, Johansson H, Strom O, Borgstrom F, Oden A (2008) Case finding for the management of osteoporosis with FRAX® — assessment and intervention thresholds for the UK. Osteoporos Int 19:1395-1408

26. Shepstone L, Fordham R, Lenaghan E et al (2012) A pragmatic randomised controlled trial of the effectiveness and costeffectiveness of screening older women for the prevention of fractures: rationale, design and methods for the SCOOP study. Osteoporos Int 23:2507-2515

27. Javaid MK, Rai S, Schoo R, Stanley R, Vasilakis N, Tsang C (2016) Fracture Liaison Service (FLS) Database facilities audit. FLS breakpoint: opportunities for improving patient care following a fragility fracture. Royal College of Physicians, London

28. Hiligsmann M, Evers SM, Ben Sedrine W, Kanis JA, Ramaekers B, Reginster JY, Silverman S, Wyers CE, Boonen A (2015) A systematic review of cost-effectiveness analyses of drugs for postmenopausal osteoporosis. PharmacoEconomics 33:205-224

29. Services PaPC (2014) Quality and outcomes framework-prevalence, achievements and exceptions report: England, 2013-14. In Centre HaSCI (ed). Health and Social Care Information Centre

30. Compston J (2015) Overdiagnosis of osteoporosis: fact or fallacy? Osteoporos Int 26:2051-2054

31. Black DM, Cummings SR, Karpf DB et al (1996) Randomised trial of effect of alendronate on risk of fracture in women with existing vertebral fractures. Fracture Intervention Trial Research Group. Lancet 348:1535-1541

32. Reynolds K, Muntner P, Cheetham TC, Harrison TN, Morisky DE, Silverman S, Gold DT, Vansomphone SS, Wei R, O'Malley CD (2013) Primary non-adherence to bisphosphonates in an integrated healthcare setting. Osteoporos Int 24:2509-2517

33. Li L, Roddam A, Gitlin M, Taylor A, Shepherd S, Shearer A, Jick S (2012) Persistence with osteoporosis medications among postmenopausal women in the UK General Practice Research Database. Menopause 19:33-40

34. Klop C, Welsing PM, Elders PJ, Overbeek JA, Souverein PC, Burden AM, van Onzenoort HA, Leufkens HG, Bijlsma JW, de Vries F (2015) Long-term persistence with anti-osteoporosis drugs after fracture. Osteoporos Int 26:1831-1840

35. Drew S, Judge A, Cooper C, Javaid MK, Farmer A, GoobermanHill R (2016) Secondary prevention of fractures after hip fracture: a qualitative study of effective service delivery. Osteoporos Int

36. Tafaro L, Nati G, Leoni E, Baldini R, Cattaruzza MS, Mei M, Falaschi P (2013) Adherence to anti-osteoporotic therapies: role and determinants of "spot therapy". Osteoporos Int 24:2319-2323

37. Curtis JR, Cai Q, Wade SW, Stolshek BS, Adams JL, Balasubramanian A, Viswanathan HN, Kallich JD (2013) Osteoporosis medication adherence: physician perceptions vs. patients' utilization. Bone 55:1-6

38. Bianchi ML, Duca P, Vai S et al (2015) Improving adherence to and persistence with oral therapy of osteoporosis. Osteoporos Int 26: $1629-1638$

39. Solomon DH, Iversen MD, Avorn J et al (2012) Osteoporosis telephonic intervention to improve medication regimen adherence: a large, pragmatic, randomized controlled trial. Arch Intern Med 172: $477-483$

40. Tuzun S, Akyuz G, Eskiyurt N et al (2013) Impact of the training on the compliance and persistence of weekly bisphosphonate treatment in postmenopausal osteoporosis: a randomized controlled study. International journal of medical sciences 10:1880-1887

41. Silverman SL, Siris E, Kendler DL et al (2015) Persistence at 12 months with denosumab in postmenopausal women with osteoporosis: interim results from a prospective observational study. Osteoporos Int 26:361-372

42. Hadji P, Papaioannou N, Gielen E et al (2015) Persistence, adherence, and medication-taking behavior in women with postmenopausal osteoporosis receiving denosumab in routine practice in Germany, Austria, Greece, and Belgium: 12-month results from a European non-interventional study. Osteoporos Int 26:2479-2489 
43. Marsh D, Akesson K, Beaton DE, Bogoch ER, Boonen S, Brandi ML, McLellan AR, Mitchell PJ, Sale JE, Wahl DA (2011) Coordinator-based systems for secondary prevention in fragility fracture patients. Osteoporos Int 22:2051-2065

44. Eisman JA, Bogoch ER, Dell R, Harrington JT, McKinney RE, Jr., McLellan A, Mitchell PJ, Silverman S, Singleton R, Siris E (2012)
Making the first fracture the last fracture: ASBMR task force report on secondary fracture prevention. J Bone Miner Res

45. Association BO (2007) The care of patients with fragility fractures

46. Akesson K, Marsh D, Mitchell PJ, McLellan AR, Stenmark J, Pierroz DD, Kyer C, Cooper C, Group IOFFW (2013) Capture the fracture: a best practice framework and global campaign to break the fragility fracture cycle. Osteoporos Int 24:2135-2152 